\title{
Report of the Korean Association of External Quality Assessment Service on Therapeutic Drug Monitoring and Toxicology (2015-2019)
}

\author{
Hyun-Ki Kim ${ }^{1}$, Dae-Hyun Ko르, Tae-Dong Jeong ${ }^{3}$, Eun Suk Shin ${ }^{4}$, Jeong-Ho Kim ${ }^{5}$, and Sail Chun ${ }^{2}$ \\ ${ }^{1}$ Department of Laboratory Medicine, Ulsan University Hospital, University of Ulsan College of Medicine, Ulsan; ${ }^{2}$ Department of \\ Laboratory Medicine, Asan Medical Center, University of Ulsan College of Medicine; ${ }^{3}$ Department of Laboratory Medicine, Ewha \\ Womans University School of Medicine; ${ }^{4}$ Department of Laboratory Medicine, Asan Medical Center; ${ }^{5}$ Department of Laboratory \\ Medicine, Severance Hospital, Yonsei University College of Medicine, Seoul, Korea
}

\section{Corresponding author:}

Sail Chun

Department of Laboratory Medicine, Asan Medical Center, University of Ulsan College of Medicine, 88 Olympic-ro 43gil, Songpa-gu, Seoul 05505, Korea Tel $+82-2-3010-4513$

Fax +82-2-478-0884

E-mail sailchun@amc.seoul.kr
This is an Open Access article distributed under the terms of the Creative Commons Attribution Non-Commercial License (http://creativecommons.org/licenses/ by-nc/4.0) which permits unrestricted non-commercial use, distribution, and reproduction in any medium, provided the original work is properly cited.
Korean Association of External Quality Assessment Service offered to conduct a proficiency test program for therapeutic drug monitoring (TDM) and testing drugs of abuse (DOA), which was named as the TDM and Toxicology program. This report summarizes the results of the proficiency tests performed between 2015-2019. In the proficiency test program, low- and high-level control materials for TDM, and positive and negative control materials for testing DOA were examined in the participating laboratories. The number of participating laboratories for TDM increased from 105 in 2015 (1st trial) to 114 in 2019 (2nd trial). Valproic acid was the most commonly tested substance. The most widely used TDM analyzer was the Architect i System (Abbott Laboratories, USA). The TDM proficiency test coefficients of variation for each test substance exhibit a broad range (0\%-300\%), which is mainly attributed to the test substance, concentration, or number of participating laboratories. The number of participating laboratories for DOA testing markedly increased from 35 in 2015 (1st trial) to 123 in 2019 (2nd trial). The proportion of the acceptable results ranged between $84 \%-100 \%$. In 2019 , five laboratories reported false negative results in the first trial, but later, they reported correct results in the second trial. In the proficiency test program for TDM and testing DOA during 2015-2019, the performance of participating laboratories was generally decent. However, continuous efforts to monitor and improve the quality of testing are required, which can happen only with increased participation in the proficiency test program.

(Lab Med Qual Assur 2020;42:183-193)

Key Words Quality assurance, Laboratory proficiency testing, Therapeutic drug monitoring, Drug of abuse

\section{서론}

대한임상검사정도관리협회는 1995년부터 혈중 치료적 약물농 도(therapeutic drug monitoring)검사에 대한 신빙도조사를 시 작하였다. 신빙도조사사업은 점차 확대되어 왔으며, 2007년부터
는 남용약물(drug of abuse)검사에 대한 신빙도조사를 시작하였 다[1-3]. 약물검사 신빙도조사는 2015년까지 약물검사분과위원 회에서 집행하였으나, 2016년도부터는 차세대 신빙도조사사업 출범과 함께 협회의 정규프로그램으로 통합적으로 집행되고 있다. 또한 2017년부터는 특수치료적 약물검사 세부프로그램이 추가되 
어, 현재 약물검사 프로그램은 일반치료적 약물검사, 특수치료적 약물검사, 면역억제제 치료적 약물검사, 마약성 약물검사의 4 개 세부프로그램으로 구성되어 있고, 각각 18종, 5 종, 4종, 16 종의 검 사항목이 포함되어 있다. 저자들은 2015년도부터 2019년까지 실 시되었던 치료적 약물검사 및 마약성 약물검사의 신빙도조사 결과 를 분석하여 종합적으로 보고하고자 한다. 다만 2017년도부터 시 작된 특수치료적 약물검사 세부프로그램은 추후에 별도의 보고서 에서 다루고자 한다.

\section{재료 및 방법}

\section{1. 정도관리물질 및 대상기관}

약물검사 프로그램에서는 연 2회에 걸쳐, 회차별, 항목별 로 2 개 농도의 정도관리물질을 이용하여 신빙도조사를 실시 하였다. 일반치료적 약물검사에서는 사람 혈청을 기질로 한 동 결건조 정도관리물질인 Lyphochek TDM Control (Bio-Rad Laboratories, Hercules, CA, USA)을 참여기관에 발송하였다. 면 역억제제에서는 전혈(whole blood) 기질의 액상 정도관리물질 인 Liquichek Whole Blood Immunsuppressant Control (BioRad Laboratories)을 참여기관에 발송하였다. 그리고 마약성 약 물검사에는 사람 소변 기질의 액상 정도관리물질인 Liquichek Qualitative Urine Toxicology Control을 참여기관에 발송하였다.

동결건조 분말 검체인 Lyphocheck TDM Control은 검사 당일 에 증류수 또는 탈이온수를 용량측정 파이펫 등을 이용하여 정확 히 $5.0 \mathrm{~mL}$ 을 넣어 재구성(reconstitution)시키고 마개를 닫고 실 온에 15 분간 세워 둔 후 몇 차례 부드럽게 섞어 사용하도록 하였 다. 나머지 액상 검체는 수령 후 검사 전까지 $2^{\circ} \mathrm{C}-8^{\circ} \mathrm{C}$ 에서 냉장보 관하였다가 환자 검체와 동일하게 검사하도록 하였다.

\section{2. 신빙도조사 약물종목}

2015년부터 2019년까지 대한임상검사정도관리협회에서 실시 한 특수치료적 약물검사를 제외한 치료적 약물농도검사 신빙도 조사 약물종목은 acetaminophen, amikacin, amitriptyline, carbamazepine, digoxin, gentamicin, lithium, methotrexate, nortriptyline, phenobarbital, phenytoin, free phenytoin, salicylate, theophylline, tobramycin, valproic acid, free valproic acid, vancomycin (일반치료적 약물검사); cyclosporine, tacrolimus (FK-506), sirolimus, everolimus (면역억제제치료적 약물검사)로 제1회와 제2회차 모두 동일한 약물을 대상으로 하였다. 다만 everolimus는 2016 년부터 추가된 항목으로, 2015년 신빙도조사에는 포함되지 않았 다. 마약성 약물검사(정성) 신빙도조사종목은 d-amphetamine, methamphetamine, methylenedioxymethamphetamine, free morphine, phencyclidine, 3,4-secobarbital, 9- $\mathrm{COOH}-$ 11-nor- $\triangle 9-T H C$, benzoylecgonine, ethanol, lysergic acid diethylamide (LSD), methadone, methaqualone, nordiazepam, nortriptyline, oxazepam, propoxyphene의 16 항목으로 제 1 회와 제 2 회차 모두 동일한 약물을 대상으로 하였다.

\section{3. 결과분석 및 통계}

참가한 기관에는 개별기관에 대한 평가결과를 보여주는 기관 별 보고서와 프로그램별 전체 참여기관의 특성을 보여주는 공통 보고서를 제공하였다. 보고서에서는 각 기관에서 입력한 각 검사 항목에 대한 정보와 결과를 기반으로 통계분석을 시행한 결과를 제공하였다. 정량검사인 치료적 약물검사들의 공통보고서에는 참 여한 전체 기관의 통계(all), 프로그램에 따른 기준분류 및 구체 화된 세분류로 나누어 각각 참여기관 수, 평균(mean), 표준편차 (standard deviation, SD), 변이계수(coefficient of variance $[\mathrm{CV}], \%)$, 중앙값(median), 최소값(min), 최대값(max)을 제시 하였다. 해당 분류에 참여한 기관 수가 10 개 이상이면서 이상치 를 제거하고 남은 기관 수가 8개 이상인 경우에만 mean, SD, CV 를 제시하였다. 이상치는 해당 분류에서의 75 percentile 값(Q3) 과 25 percentile 값(Q1)의 차이(Q3-Q1; interquartile range, $\mathrm{IQR})$ 의 1.5 배를 초과하여 $\mathrm{Q} 1$ 보다 낮거나 $\mathrm{Q} 3$ 보다 높은 결과값 (<Q1-1.5 $\times$ IQR or $>\mathrm{Q} 3+1.5 \times 1 \mathrm{QR})$ 으로 선정하여 제거하였다. Median, min, max는 이상치를 제거하지 않고 해당 분류에 참여 한 기관을 다 포함하여 제시하였다. 기관 수가 2 개인 경우 $\mathrm{min}$, $\max$ 만을 제시하고, 기관 수가 1 개인 경우 median만 제시하였 다.

본 보고서에서도 회차별 결과보고서와 마찬가지로, IQR을 이 용한 이상치 제거 후 mean, SD, CV 값을 계산하여 제시하였다. 하지만 적은 참가기관 수에 비하여 다양한 검사기기들이 사용되 는 프로그램의 특성을 고려하여 일부 세부분류는 통합하여 통계 치를 제시하였고, 기관 수가 2개 이상인 경우 모두 mean, SD, $\mathrm{CV}$ 값을 제시하였다. 결과분석 및 통계처리에는 Microsoft Excel 2019 (Microsoft Corp., Redmond, WA, USA) 프로그램과 R ver. 3.6.3. (R Foundation for Statistical Computing, Vienna, Austria) 프로그램을 사용하였다.

\section{결과}

\section{1. 치료적 약물검사의 신빙도조사 참여기관 및 검사종목}

2015년 1회차와 비교하여 2019년 2회차 참여기관 수의 변화 를 살펴보았을 때, tacrolimus (+28.1\%), sirolimus (+50.0\%) 
와 같은 면역억제제 항목들의 참여기관 증가가 두드러졌다(Table 1). 반면, theophylline (-44.2\%)은 참여기관 수가 상당히 감소 하였다. 2019년도에는 치료적 약물검사 신빙도조사에 1회차 113 개 기관, 2 회차 114 개 기관이 참여하였는데, 가장 많은 기관에 서 참여한 약물농도 검사항목은 valproic acid로, 1 회차 84 개, 2 회차 84 개 기관에서 참여하였다. 다음으로 참여기관이 많은 검 사항목은 vancomycin과 tacrolimus로, 1 회차 $70 / 72$ 개, 2회차 $74 / 73$ 개 기관에서 각각 참여하였다. 검사코드가 개설된 항목들 중 amitriptyline과 nortriptyline은 응답한 기관이 없었다.

\section{2. 치료적 약물검사의 신빙도조사 결과보고에 이용된 검사 장비}

치료적 약물검사 신빙도조사 결과보고에 이용된 검사장비 는 Architect i System (Abbott Laboratories, Chicago, IL, USA)가 5개년 동안 $46.4 \%-45.1 \%$ 로 가장 비율이 높았다. 2015
년도에는 Cobas Integra (Roche Diagnostics, Mannheim, Germany)가 $18.0 \%$ 로 두번째로 비율이 높았으나, Cobas c311/ c501/c502/c702 modules (Roche Diagnostics)의 증가와 함 께 2019년도에는 5.7\%로 감소하였다(Table 2). 검사기기의 종 류는 다양했지만 액체크로마토그래피-탠덤질량분석법(liquid chromatography-tandem mass spectrometry, LC-MS/MS) 을 이용한 보고비율도 2019년 기준 $10.1 \%$ 로 2015년도(1.8\%)와 비교해 많이 증가하였다.

\section{3. 치료적 약물검사의 신빙도조사 결과의 통계}

치료적 약물검사의 검사항목별, 검체의 농도별 $\mathrm{CV}$ 를 Table 3에 정리하였다. 2019년도의 신빙도조사 $\mathrm{CV}$ 의 전체 평균은 1 회차에 서 저농도 $28.4 \%$, 고농도 $13.2 \%$ 였고, 2 회차에서 저농도 $23.8 \%$, 고농도 $12.7 \%$ 로 높게 나타났으나, 참여검사실 수가 5 개 이하 인 gentamicin, salicylate, tobramycin, itraconazole, $4-\mathrm{OH}$

Table 1. Number of laboratories that participated in each therapeutic drug monitoring proficiency testing during 2015-2019

\begin{tabular}{|c|c|c|c|c|c|c|c|c|c|c|c|}
\hline \multirow{3}{*}{ Test substances } & \multicolumn{10}{|c|}{ Year } & \multirow{3}{*}{$\begin{array}{c}\text { \%Change } \\
\text { (2019-2nd } \\
\text { vs 2015- } \\
1 \text { st) }\end{array}$} \\
\hline & \multicolumn{2}{|c|}{2015} & \multicolumn{2}{|c|}{2016} & \multicolumn{2}{|c|}{2017} & \multicolumn{2}{|c|}{2018} & \multicolumn{2}{|c|}{2019} & \\
\hline & 1 st & 2nd & $1 \mathrm{st}$ & 2nd & $1 \mathrm{st}$ & 2nd & $1 \mathrm{st}$ & 2nd & 1 st & 2nd & \\
\hline Acetaminophen & 6 & 5 & 5 & 5 & 6 & 6 & 6 & 6 & 6 & 6 & 0.0 \\
\hline Amikacin & 6 & 5 & 6 & 6 & 6 & 6 & 6 & 6 & 6 & 6 & 0.0 \\
\hline Carbamazepine & 51 & 47 & 44 & 41 & 42 & 42 & 41 & 40 & 39 & 38 & -25.5 \\
\hline Digoxin & 73 & 70 & 67 & 66 & 70 & 69 & 65 & 62 & 60 & 59 & -19.2 \\
\hline Gentamicin & 5 & 5 & 5 & 5 & 5 & 5 & 5 & 4 & 5 & 5 & 0.0 \\
\hline Lithium & 34 & 35 & 28 & 31 & 32 & 33 & 33 & 33 & 35 & 33 & -2.9 \\
\hline Methotrexate & 17 & 17 & 15 & 15 & 17 & 17 & 19 & 19 & 19 & 18 & 5.9 \\
\hline Phenobarbital & 34 & 32 & 31 & 28 & 29 & 29 & 27 & 27 & 24 & 22 & -35.3 \\
\hline Phenytoin & 50 & 47 & 47 & 43 & 44 & 43 & 41 & 40 & 38 & 37 & -26.0 \\
\hline Phenytoin, free & 1 & 1 & 1 & 1 & 1 & 1 & 1 & 1 & 1 & 1 & 0.0 \\
\hline Salicylate & 4 & 3 & 3 & 3 & 3 & 3 & 3 & 3 & 3 & 3 & -25.0 \\
\hline Theophylline & 43 & 41 & 36 & 36 & 35 & 32 & 29 & 28 & 27 & 24 & -44.2 \\
\hline Tobramycin & 3 & 3 & 3 & 3 & 3 & 3 & 3 & 3 & 3 & 3 & 0.0 \\
\hline Valproic acid & 90 & 90 & 86 & 82 & 85 & 85 & 85 & 84 & 84 & 84 & -6.7 \\
\hline Valproic acid, free & 1 & 1 & 2 & 3 & 3 & 3 & 3 & 3 & 2 & 2 & 100.0 \\
\hline Vancomycin & 57 & 59 & 63 & 62 & 66 & 67 & 71 & 70 & 70 & 74 & 29.8 \\
\hline Cyclosporine & 47 & 48 & 48 & 46 & 48 & 47 & 47 & 48 & 50 & 52 & 10.6 \\
\hline Everolimus & - & - & 8 & 8 & 8 & 8 & 10 & 10 & 11 & 12 & - \\
\hline Sirolimus & 10 & 11 & 12 & 12 & 12 & 12 & 14 & 14 & 14 & 15 & 50.0 \\
\hline Tacrolimus (FK506) & 57 & 59 & 60 & 61 & 66 & 65 & 67 & 68 & 72 & 73 & 28.1 \\
\hline Total no. of institutions & 105 & 106 & 103 & 104 & 110 & 110 & 110 & 110 & 113 & 114 & 8.6 \\
\hline
\end{tabular}


Table 2. Percentage of the instruments used for the therapeutic drug monitoring proficiency testing during 2015-2019

\begin{tabular}{|c|c|c|c|c|c|}
\hline \multirow{2}{*}{ Name of instrument } & \multicolumn{5}{|c|}{ Year } \\
\hline & 2015 & 2016 & 2017 & 2018 & 2019 \\
\hline Abbott Architect i System & 46.4 & 49.2 & 46.9 & 47.4 & 45.1 \\
\hline Roche Cobas c311/c501/c502/c702 & 6.0 & - & 5.0 & 11.8 & 17.2 \\
\hline LC-MS/MS & 1.8 & 4.3 & 6.7 & 8.2 & 10.1 \\
\hline Roche Cobas Integra & 18.0 & 18.6 & 16.9 & 11.1 & 5.7 \\
\hline Siemens Dimension & 3.7 & 2.9 & 3.7 & 4.2 & 5.4 \\
\hline Roche Cobas E170/e411/e601/e602/e801 & - & 4.5 & 4.3 & 4.4 & 4.0 \\
\hline Siemens ADVIA Centaur & 3.2 & 3.9 & 4.2 & 4.0 & 3.4 \\
\hline Beckman Olympus AU Series & 1.0 & 1.6 & 1.4 & 1.4 & 1.6 \\
\hline Ortho Vitros5600 & - & 0.2 & - & - & 1.1 \\
\hline Roche AVL9180 & - & 0.3 & 0.7 & 0.8 & 1.0 \\
\hline Nova 4 Analyzer & - & - & 0.6 & 0.7 & 0.9 \\
\hline Roche/Hitachi Systems & 3.8 & 1.2 & 0.9 & 0.7 & 0.7 \\
\hline Toshiba Chemistry Analyzer & 1.2 & 0.7 & 0.3 & 0.3 & 0.7 \\
\hline Roche 9100 Series (ISE mode) & 0.2 & 0.8 & 0.7 & 0.7 & 0.5 \\
\hline ICP-MS & 0.1 & 0.2 & 0.2 & 0.2 & 0.2 \\
\hline Hitachi AP720 & - & - & 0.9 & 0.2 & 0.2 \\
\hline Atomic Absorption Spectrometers & 0.3 & 0.4 & 0.2 & 0.2 & 0.2 \\
\hline Radioimmunoassay & 0.3 & 0.2 & 0.2 & 0.2 & 0.2 \\
\hline Siemens Viva-E & 2.2 & 1.1 & 1.0 & 0.2 & 0.2 \\
\hline Beckman UniCel DxI800 & - & 1.1 & 0.2 & 0.2 & 0.1 \\
\hline Siemens Vista & 0.7 & 0.5 & 0.3 & 0.2 & 0.1 \\
\hline Siemens Atellica CH 930 Analyzer & - & - & - & - & 0.1 \\
\hline GC-MS & - & - & - & 0.1 & - \\
\hline Beckman UniCel DxC Synchron & 3.3 & 1.7 & 0.2 & - & - \\
\hline Others & 7.8 & 6.7 & 4.7 & 3.2 & 1.6 \\
\hline Total & 100.0 & 100.0 & 100.0 & 100.0 & 100.0 \\
\hline
\end{tabular}

Values are presented as \%. The instruments were from the following companies: Abbott Laboratories (Chicago, IL, USA), Roche Diagnostics (Mannheim, Germany), Siemens (Erlangen, Germany), Beckman Coulter Inc. (Brea, CA, USA), Ortho Clinical Diagnostics (Raritan, NJ, USA), Nova Biomedical Corp. (Waltham, MA, USA), Toshiba Medical Systems (Tokyo, Japan), and Hitachi High-Technologies Corp. (Tokyo, Japan). Instruments of the same series are combined, and some minor instruments with various manufacturers are substituted as their methods: liquid chromatography-tandem mass spectrometry (LC-MS/MS), inductively coupled plasma-mass spectrometry (ICP-MS), radioimmunoassay, gas chromatography-mass spectrometry (GC-MS), and atomic absorption spectrometry.

itraconazole과 저농도 검체가 0에 가까운 매우 낮은 농도였던 everolimus를 제외하면, 1 회차에서 저농도 $8.1 \%$, 고농도 $6.7 \%$ 였고, 2 회차에서 저농도 $9.5 \%$, 고농도 $7.0 \%$ 였다. 2019 년도의 검 사항목별 신빙도조사 결과는 장비를 고려하지 않은 전체 참가기관 의 mean, $\mathrm{SD}$ 및 $\mathrm{CV}$ 와 검사장비를 고려한 mean, $\mathrm{SD}$ 및 $\mathrm{CV}$ 를 구 분하여 요약하였다(Tables 4, 5).

\section{4. 마약성 약물검사}

마약성 약물검사 신빙성조사에 참여한 기관 수는 2015년도에 1 차 35 기관, 2 차 38 기관이었으나, 2016년 1차 72 기관, 2차 71 기관, 2017년 1차 86기관, 2차 96기관, 2018년 1차 109기관, 2 차 111 기관으로 점차 증가하여 2019년에는 1차 124기관, 2차 123 기관에 이르렀다. 2019년도 신빙도조사 결과를 살펴보면, 1 회차에서는 methylenedioxymethamphetamine에 대해 양 


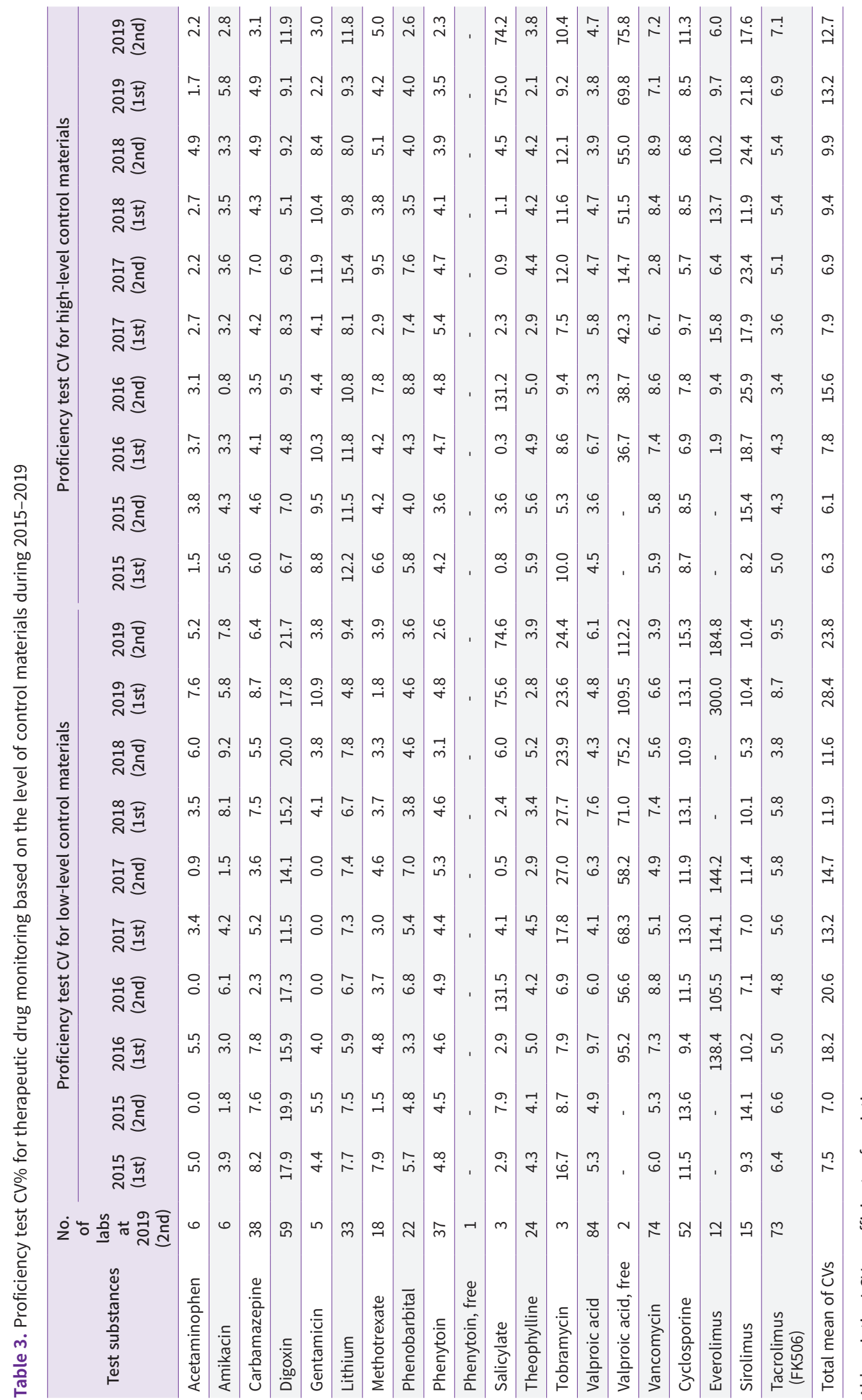




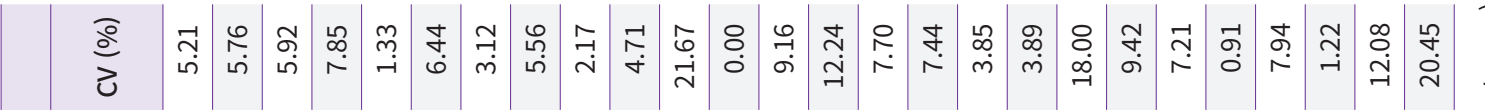

ఫ

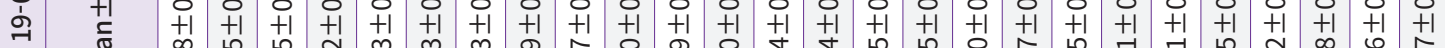

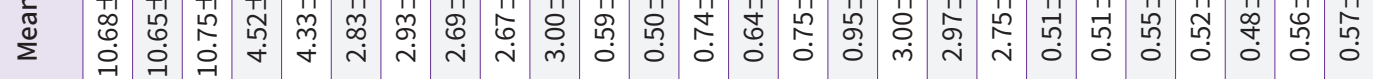

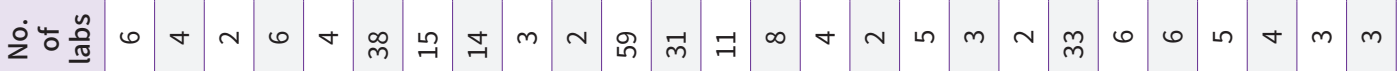

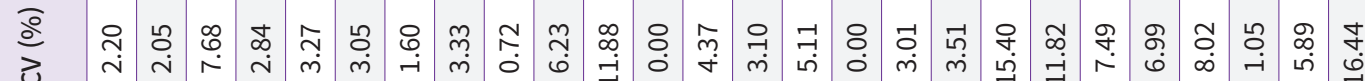

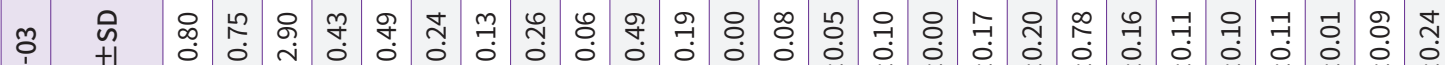

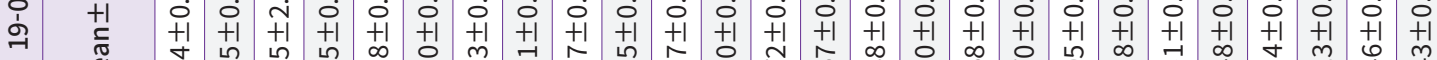

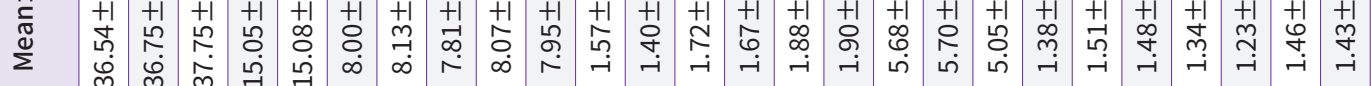

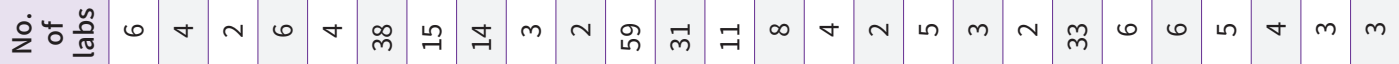

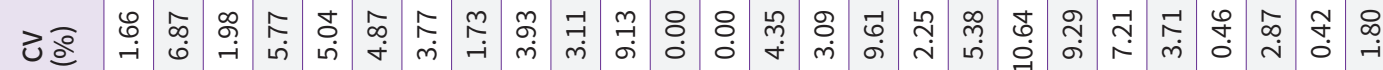

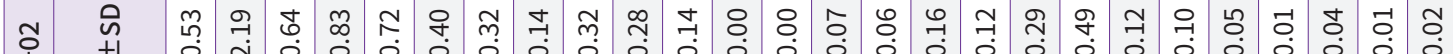

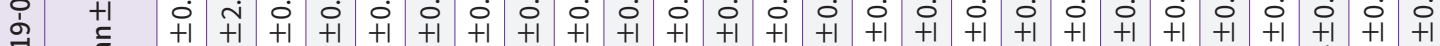

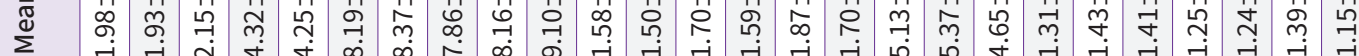

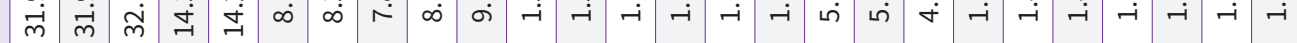

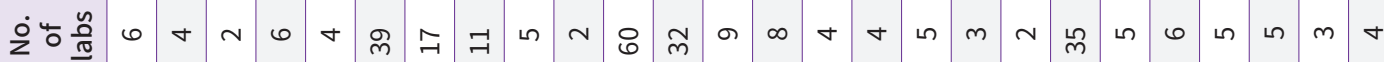

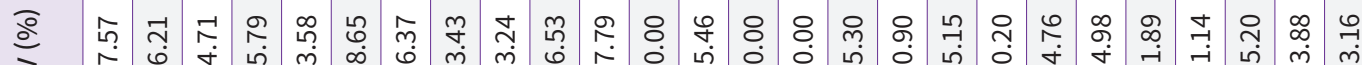

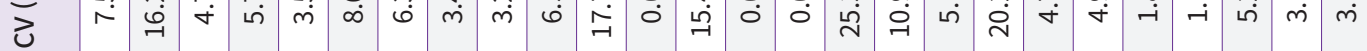

- 0 ค

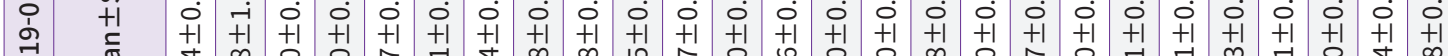

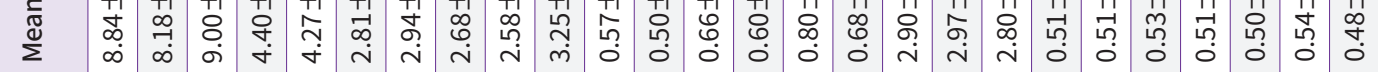

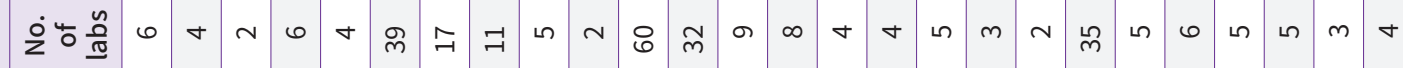
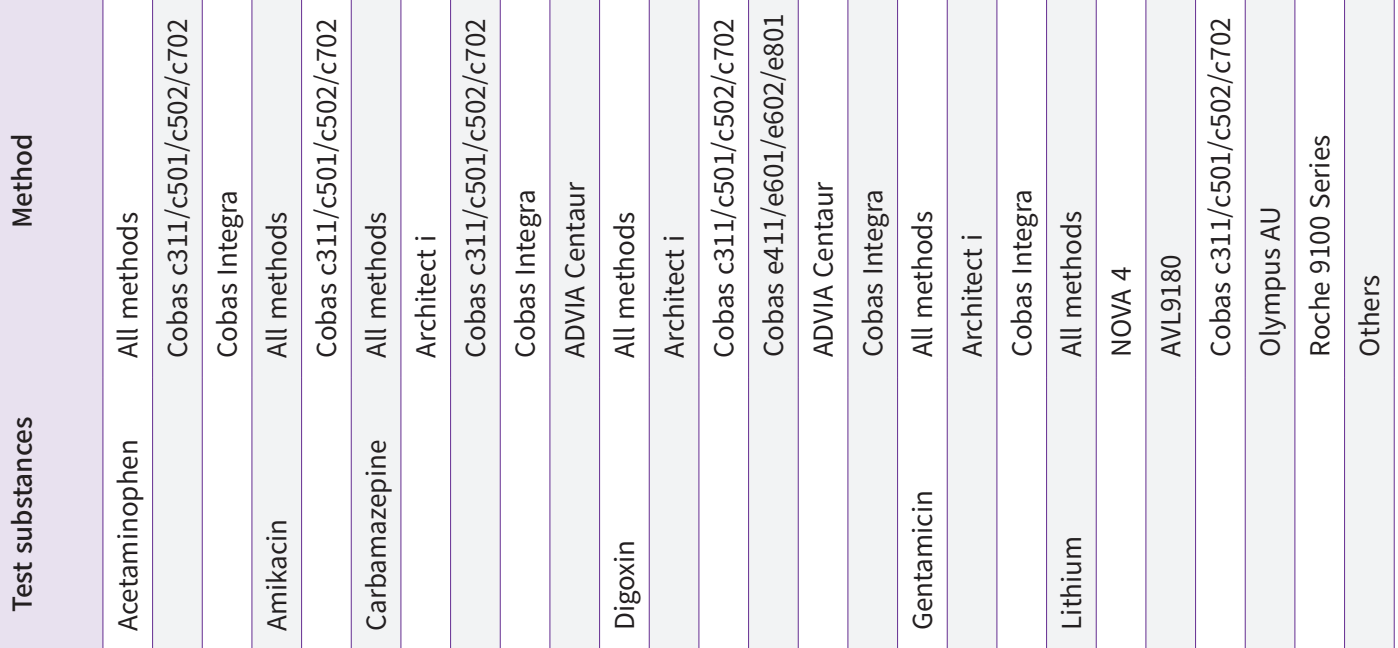

高 


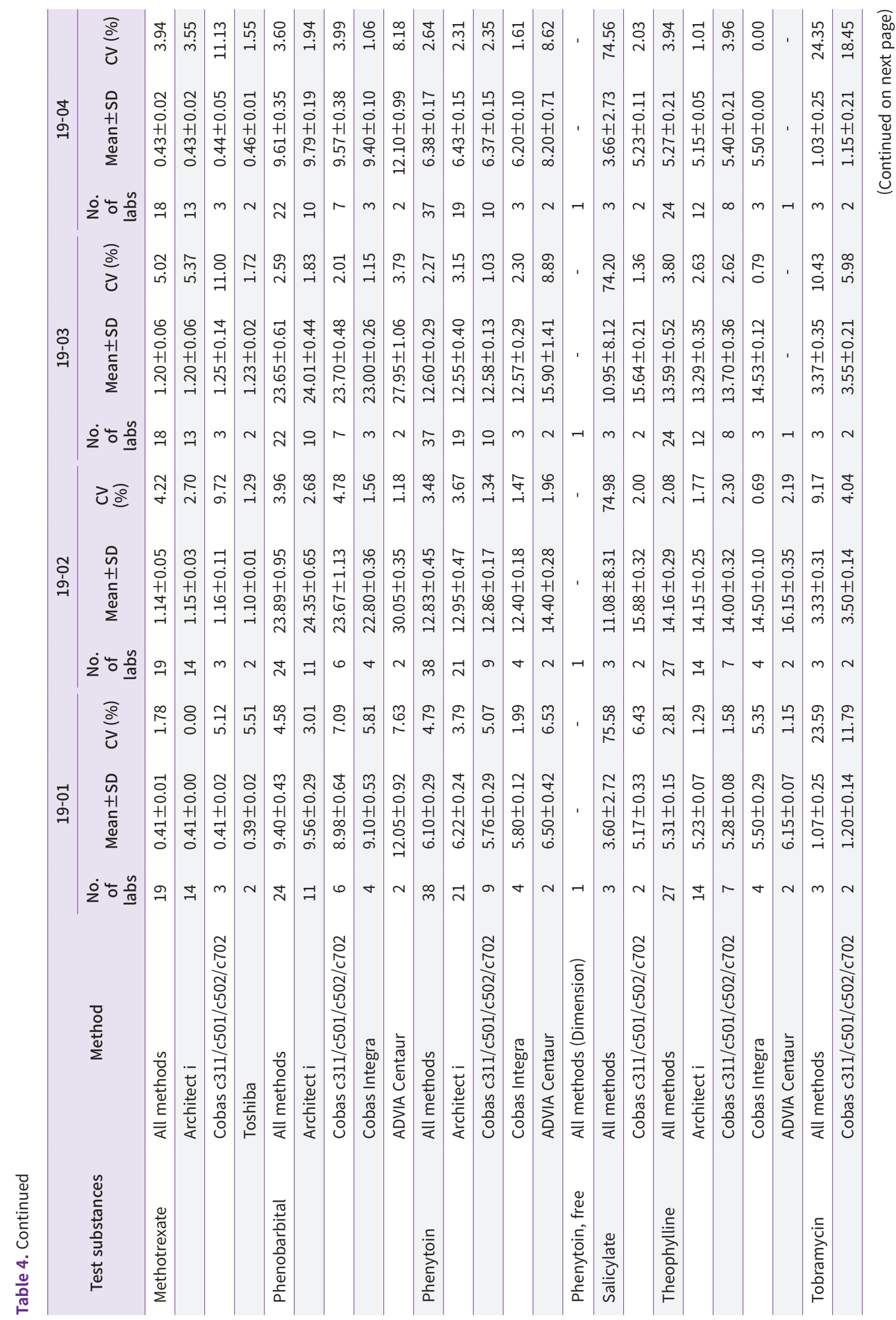




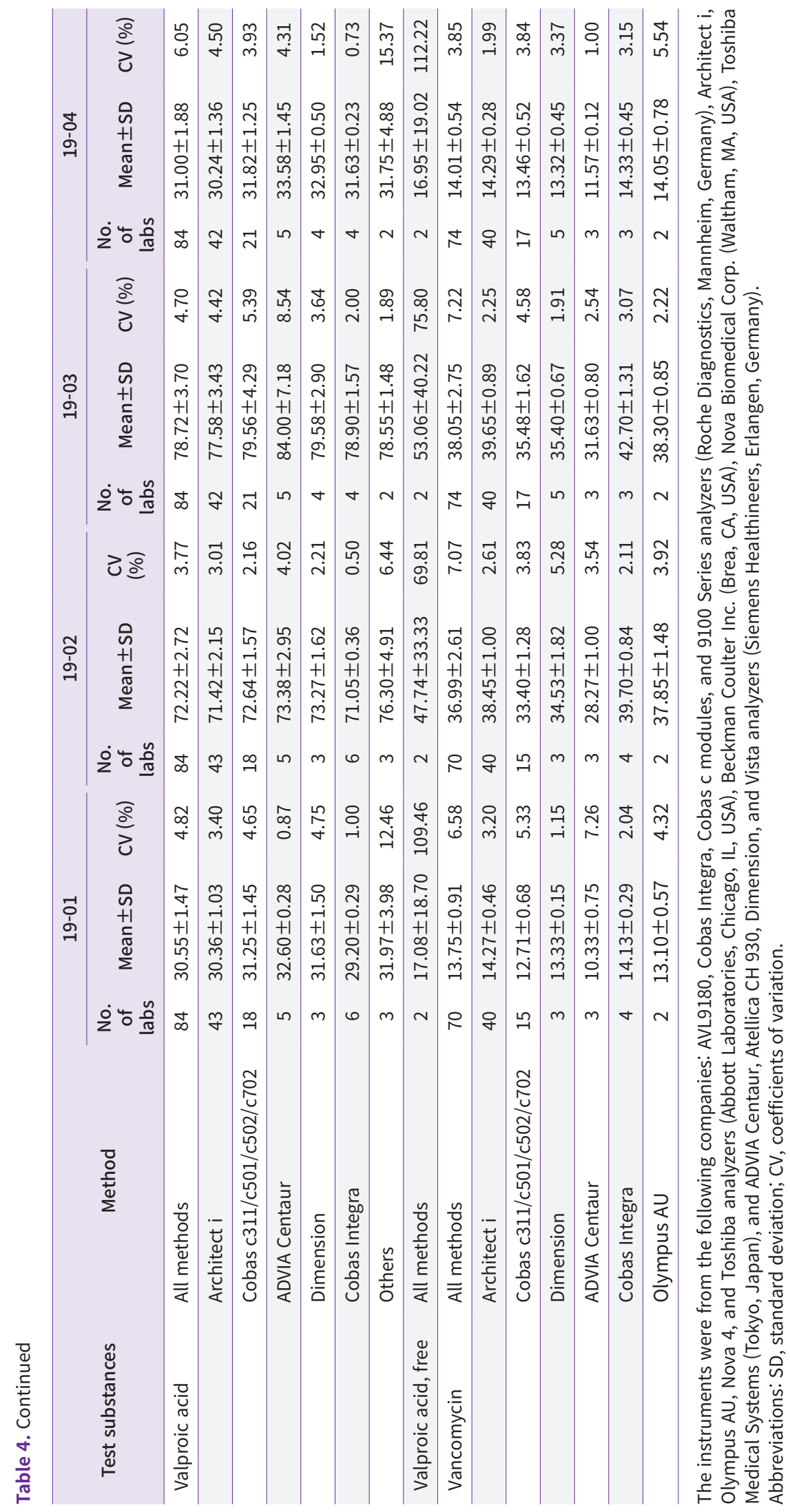




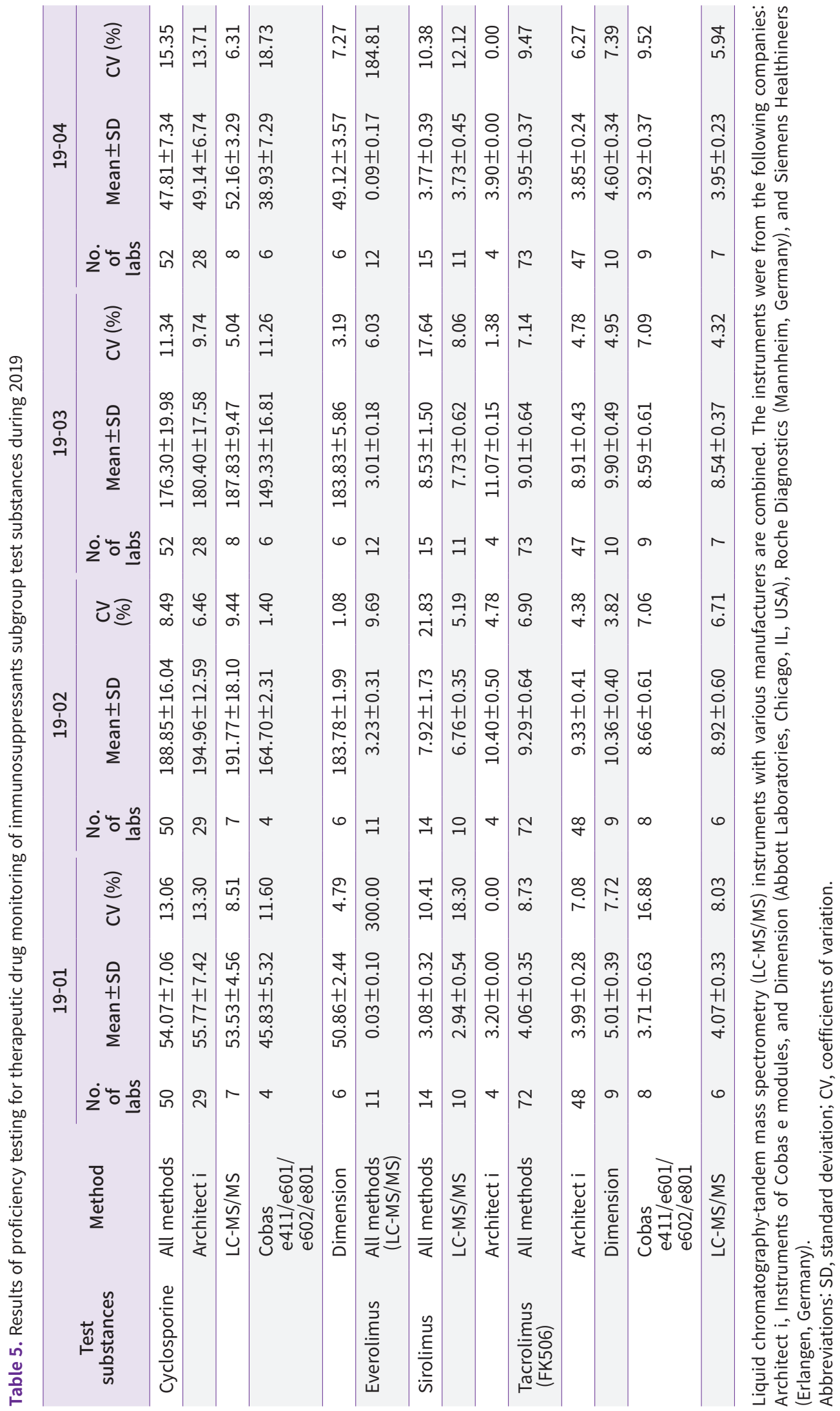


Table 6. Number of participating laboratories with the percentage of results that were acceptable results in the proficiency test for drugs of abuse during 2019

\begin{tabular}{lccccc}
\hline \multirow{2}{*}{ Test substances } & \% Range & \multicolumn{4}{c}{ During 2019 } \\
\cline { 4 - 6 } & $(2015-2018)$ & $19-01$ & $19-02$ & $19-03$ & $19-04$ \\
\hline Methamphetamine & $94.6-100$ & $121(99.2)$ & $121(99.2)$ & $120(98.3)$ & $120(98.3)$ \\
\hline 9-COOH-11-nor- $\triangle$ 9-THC & $94.6-100$ & $110(100)$ & $110(99.1)$ & $110(97.3)$ & $110(98.2)$ \\
\hline Morphine, Free & $96.6-100$ & $111(99.1)$ & $111(99.1)$ & $110(98.2)$ & $110(98.2)$ \\
\hline Benzoylecgonine & $95.9-100$ & $102(100)$ & $102(100)$ & $103(98.1)$ & $103(98.1)$ \\
\hline d-Amphetamine & $87.5-100$ & $79(100)$ & $79(97.5)$ & $78(97.4)$ & $78(98.7)$ \\
\hline Methylenedioxymethamphetamine & $84.0-100$ & $60(100)$ & $60(91.7)$ & $62(96.8)$ & $62(98.4)$ \\
\hline Phencyclidine & $100-100$ & $22(100)$ & $22(100)$ & $22(100)$ & $22(100)$ \\
\hline Methadone & $100-100$ & $17(100)$ & $17(100)$ & $17(100)$ & $17(100)$ \\
\hline Nordiazepam & $100-100$ & $13(100)$ & $13(100)$ & $15(100)$ & $15(100)$ \\
\hline Oxazepam & $100-100$ & $15(100)$ & $15(100)$ & $15(100)$ & $15(100)$ \\
\hline 3,4-Secobarbital & $100-100$ & $8(100)$ & $8(100)$ & $12(100)$ & $12(100)$ \\
\hline Nortriptyline & $100-100$ & $11(100)$ & $11(100)$ & $12(100)$ & $12(100)$ \\
\hline Ethanol & $100-100$ & $4(100)$ & $4(100)$ & $4(100)$ & $4(100)$ \\
\hline Propoxyphene & $100-100$ & $3(100)$ & $3(100)$ & $3(100)$ & $3(100)$ \\
\hline Lysergic acid diethylamide (LSD) & $100-100$ & $2(100)$ & $2(100)$ & $2(100)$ & $2(100)$ \\
\hline
\end{tabular}

Values are presented as number (\%).

성 검체(CDT-19-02)를 음성으로 5개 기관에서 보고하였다. 또 한 d-Amphetamine, 9-COOH-11-nor- $\triangle 9$-THC에 대해서도 각 각 2 개, 1 개 기관이 양성 검체를 음성으로 보고하였다. 한 기관 에서 methamphetamine과 free morphine에 대해 CDT-1901, CDT-19-02 두 검체 모두 결과를 반대로 응답하였고, 사무적 오류가 의심되었다. 2회차에서는 한 기관이 d-amphetamine, methamphetamine, methylenedioxymethamphetamine, free morphine, 9-COOH-11-nor- $\triangle$ 9-THC, benzoylecgonine 에 대해 CDT-19-03, CDT-19-04 두 검체 모두 결과를 반대로 응답하였고, 다른 한 기관에서도 methamphetamine, free morphine, 9-COOH-11-nor- $\triangle$ 9-THC, benzoylecgonine 에 대해 두 검체 모두 결과를 반대로 응답하였다. 이 외에 d-Amphetamine, Methylenedioxymethamphetamine, 9-COOH-11-nor- $\triangle$ 9-THC에 대해 각각 한 개의 기관들이 양성 검체(CDT-19-03)를 음성으로 보고하였다. 그 외 대부분의 기관에 서는 의도한 답과 동일하게 응답하였다(Table 6).

\section{고찰}

대한임상정도관리협회의 치료적 약물검사 신빙도조사사업에 참여한 기관의 수는 사업이 시작된 이후 2007년까지 꾸준히 증가
하다가 이후 유사한 수준을 보였다[4]. 2019년 참여기관 수는 1 회차에 113 개, 2회차에 114 개 기관으로 2015년에 비해 8개 기 관이 증가하였다. 검사항목별로는 acetaminophen, lithium, methotrexate, vancomycin, cyclosporine, everolimus, sirolimus, tacrolimus들에 대한 참여기관은 2016년에 비 해 증가된 반면 carbamazepine, digoxin, phenobarbital, phenytoin, theophylline, valproic acid들의 참여기관 수가 다 소 감소하였다. 특히 면역억제제 중 tacrolimus는 꾸준히 참여기 관이 증가하고 있는데, 이는 장기 이식이 활성화되고 환자가 누적 되고 있는 상황을 반영하는 것으로 생각된다. 반면, theophylline 은 꾸준히 참여기관이 감소하고 있는데, 이는 천식 치료에서의 역 할이 축소됨에 따라 사용이 감소하였기 때문일 것으로 생각된다.

2019년도의 신빙도조사 CV를 살펴보면, salicylate 저농도와 고농도, free valproic acid 저농도와 고농도, everolimus 저농 도에서 예년에 비해 크게 증가한 CV를 보이며, 전체 평균 CV의 증 가를 가져왔다. 하지만 salicylate의 경우 한 기관에서 다른 기관 에 비해 모든 결과를 한 자릿수 작게 보고하여 사무적 오류가 의 심되었고, free valproic acid는 두 개 기관만 참여한 결과이며, everolimus는 다수의 기관에서 음성으로 결과를 보고한 매우 낮 은 농도의 물질이 사용되었다. 따라서 이러한 점을 고려해볼 때 평 균 $\mathrm{CV}$ 의 증가가 검사실 간 정밀도의 악화를 의미한다고 보기는 
어렵다고 생각된다. 참여기관 수가 많은 valproic acid $(n=84)$ 의 경우 3.77\%-6.05\%의 우수한 CV 값을 보였으며, vancomycin $(\mathrm{n}=70-74)$ 의 경우 $3.85 \%-7.22 \%$, tacrolimus $(\mathrm{n}=72-73)$ 의 경 우 6.90\%-9.47\%의 양호한 CV 값을 보였다.

마약성 약물검사 신빙도조사는 소변 정성검사에 대한 것으 로, 양성 및 음성 정도관리물질 농도 차이가 매우 크므로 오 답을 보고한 기관은 사무적 오류가 있었는지 여부를 검토하 고 검사시약의 보관상태 및 검사의 cut-off 등을 점검할 필 요가 있다. 참여기관 수는 2015년도에 1차 35기관, 2차 38 기관에서 2019년도에 1차 124기관, 2차 123기관으로 대 폭 증가하였다. 2019년도 신빙도조사 결과를 살펴보면, 1 회 차 methylenedioxymethamphetamine에 대해 양성 검체 (CDT-19-02)를 음성으로 5개 기관에서 보고하였으나 2회차에
서는 정답을 보고하였다. 하지만 2 회차에서도 다른 한 기관에서 methylenedioxymethamphetamine에 대해 양성 검체(CDT19-03)를 음성으로 보고하는 등 산발적으로 오답을 보고하는 경 우가 있었다.

결론적으로, 치료적 약물농도검사 신빙도조사의 참여기관 수는 최근 5년간 다소 증가하였고, 신빙도조사 평균 $\mathrm{CV}$ 값은 다소 증가 하였으나 사무적 오류 및 물질의 매우 낮은 농도를 고려하였을 때 이것이 검사실 간 정밀도의 악화를 의미한다고 보기는 어렵다. 마 약성 약물검사는 오답을 내는 기관이 적지만 산발적으로 발생하고 있어 각 기관에서 보다 주의할 필요가 있겠다. 약물검사는 환자 개 개인의 적정약물요법 및 약물남용 관리를 위해 필수적인 검사로 각 검사실에서는 지속적인 신빙도조사사업 참여를 통하여 검사의 질을 높여 나가야 한다.

\section{REFERENCES}

1. Kim JQ, Jung YS, Kwon OH, Kwon HJ, Kim YK, Kim JW, et al. Annual report on 2008 external quality assessment in therapeutic drug monitoring in Korea (1995). J Clin Pathol Qual Control 2009;18:119-25.

2. Kim JH, Kim BK, Lee SY, Chun S, Kwon GC, Yoon Y, et al. Annual report on external quality assessment in therapeutic drug monitoring and drug of abuse in Korea (2007). J Lab Med Qual Assur 2008;30:133-49.

3. Jeong TD, Gu GG, Chun S, Kim JH; Therapeutic Drug Monitoring Subcommittee, The Korean Association of Quality Assurance for Clinical Laboratory. Annual report on the external quality assessment of therapeutic drug monitoring and testing for drugs of abuse in Korea (2013). J Lab Med Qual Assur 2014;36:12-22.

4. Ko DH, Jeong TD, Gu GG, Chun S, Kim JH. Annual report on the external quality assessment scheme for therapeutic drug monitoring and testing for drugs of abuse in Korea (2014). J Lab Med Qual Assur 2015;37:12-22. 